\title{
Use of alternative curing salts for processing salamis
}

\author{
Dong-Gyun Yim', Ku-Young Chung' ${ }^{2}$, Cheorun Jo ${ }^{3}$, and Ki-Chang Nam ${ }^{4, *}$
}

\section{* Corresponding Author: Ki-Chang Nam Tel: +82-61-750-3231, Fax: +82-61-750-3230 E-mail: kichang@scnu.kr}

'Department of Health Administration and Food Hygiene, Jinju Health College, Jinju 52655, Korea 2 Department of Animal Science and Biotechnology, Sangji University, Wonju 26339, Korea

${ }^{3}$ Department of Agricultural Biotechnology, Center for Food and Bioconvergence, and Research Institute of Agriculture and Life Science, Seoul National University, Seoul 08826, Korea

${ }^{4}$ Department of Animal Science and Technology, Sunchon National University, Suncheon 57922, Korea

ORCID

Dong-Gyun Yim

https://orcid.org/0000-0002-6519-0859

Ku-Young Chung

https://orcid.org/0000-0002-5734-5128

Cheorun Jo

https://orcid.org/0000-0002-3166-1608

Ki-Chang Nam

https://orcid.org/0000-0002-2432-3045

Submitted Jun 5, 2017; Revised Jul 4, 2017; Accepted Aug 2, 2017
Objective: This study was performed to determine effects of different curing salts on the quality of salamis and to assess feasibility of using $\mathrm{NaCl}$-alternative salts.

Methods: Various types of curing salts $\left(\mathrm{KCl}\right.$ or $\mathrm{MgCl}_{2}$ ) as well as $\mathrm{NaCl}$ (sun-dried or refined) were incorporated for processing of salamis. The proximate composition, fatty acids, nucleotiderelated compounds, and free amino acids of the salamis were analyzed during 40 days of ripening. Results: The substitution of $\mathrm{NaCl}$ by $\mathrm{KCl}$ caused higher fat and ash content, but lower moisture content of the salami after 20 days of ripening $(\mathrm{p}<0.05)$. Compared with the sun-dried $\mathrm{NaCl}$, use of $\mathrm{KCl}$ in salami also led to greater inosine 5'-monophosphate whereas refined $\mathrm{NaCl}$ had more inosine $(\mathrm{p}<0.05)$. KCl-added salami also had a higher C12:0, C17:1, and C20:0 than other types of salami $(\mathrm{p}<0.05)$. $\mathrm{MgCl}_{2}$-added salami had higher content of free amino acids compared to the other salamis $(\mathrm{p}<0.05)$.

Conclusion: Alternative curing salts such as $\mathrm{KCl}$ and $\mathrm{MgCl}_{2}$ could substitute $\mathrm{NaCl}$ in consideration of quality factor of a fermented meat product. Especially replacement of $\mathrm{NaCl}$ with $\mathrm{KCl}$ will be a suitable strategy for developing relatively low sodium salami products without compromising product quality.

Keywords: Salamis; Curing Salts; Nucleotides; Fatty Acids; Free Amino Acids

\section{INTRODUCTION}

Salami refers to salted meats that have been extruded into a casing and then hung to undergo aging and drying for months [1]. During production of salami, there are various types of mold on its surface [2]. The presence of molds on salami surfaces imparts its typical flavor, delays rancidity, and prevents spoilage and growth of unwanted bacteria [3].

Sodium chloride $(\mathrm{NaCl})$ contributes to microbial stability by reducing water activity, while also allowing solubilization of muscle proteins and providing a pleasant salty taste to the final meat product [4]. Although $\mathrm{NaCl}$ is a common component of the human diet, high sodium intake may result in harmful consequences to health such as increased risk of cardiovascular diseases [5]. Therefore, the demand for low sodium foods, especially meat products, has recently increased [6]. Nitrite and nitrate can be widely applied as preservatives owing to their antimicrobial activity [7] as well as their influence on color and flavor formation in cured meat products [8]. Generally, sundried or refined salts $(\mathrm{NaCl})$ are used in meat processing [9]. Sun-dried salt is naturally made by evaporating harmful substances together with moisture by wind and sunlight. This type of salt contains $92.4 \%$ to $94.4 \%$ sodium chloride as well as diverse minerals such as calcium, potassium, magnesium, and sulfur [10]. Refined salt, which contains $99.8 \%$ sodium chloride, is made by electrolyzing seawater to remove impurities and heavy metals using ionized membranes [9]. Refined salt is currently commonly employed in meat processing.

It can be tried that a possible approach to reduce the sodium content of a food product by partial or total replacement of $\mathrm{NaCl}$ with other chloride salts (e.g., $\mathrm{KCl}, \mathrm{CaCl}_{2}$, and $\mathrm{MgCl}_{2}$ ). Potassium chloride $(\mathrm{KCl})$ has been given the generally recognized as safe (GRAS) status by the Code of 
federal regulations [11], and its use in food is accepted by many international scientific bodies and regulatory authorities. Moreover, the WHO recommended dosage of $3.5 \mathrm{~g} / \mathrm{d}$ for potassium is found to be helpful in maintaining lower blood pressure levels [12]. However, the presence of other types of chloride salts has been shown to delay the decrease in water activity and thus increase the post-salting time required to reach similar water activities as in the traditional process [13]. Moreover, studies have shown that $\mathrm{KCl}$ has functional properties similar to $\mathrm{NaCl}$, but that its addition was limited due to its bitter taste in meat products [14].

The effect of using $\mathrm{NaCl}$-alternative salts in salami has not been thoroughly investigated. Moreover the quality changes of salami were not determined for relatively longer ripening and drying time. Therefore, this study was conducted to elucidate the effects of various curing salts on the physicochemical and functional characteristics of salami during the ripening process.

\section{MATERIALS AND METHODS}

\section{Salami manufacture}

For salami production, refrigerated beef topside round (semitendinosus), pork hind leg (triceps brachii), and frozen pork backfat were obtained in vacuum packaged condition from a local meat packer. Pork and beef were trimmed of visible fat, after which both meats and pork backfat were cut and weighed in appropriate amounts, vacuum packed, and frozen at $-24^{\circ} \mathrm{C}$ for 2 days. Four treatments of salamis were prepared using different curing salts (1.9\% refined salt, $1.9 \% \mathrm{KCl}, 1.9 \% \mathrm{MgCl}_{2}$ ), where $\mathrm{KCl}$ and $\mathrm{MgCl}_{2}$ were selected as they are available in market for substitution of $\mathrm{NaCl}$. The formulation mix for salami consisted of $30 \%$ beef topside round, $46 \%$ pork hind leg, $20 \%$ back fat, $1.9 \%$ salt $\left(\mathrm{NaCl}, \mathrm{KCl}\right.$, or $\left.\mathrm{MgCl}_{2}\right), 0.5 \%$ garlic, $0.1 \%$ monosodium glutamate (MSG), $0.4 \%$ glucose, $0.2 \%$ starter culture, and $0.1 \%$ sodium nitrite. Beef, pork and backfat were cut in a bowl chopper (Fujee Co., Seoul, Korea) to the desired particle size (about 3 to $5 \mathrm{~mm}$ ), then mixed in a mixer (Fujee Co., Korea). A commercial frozen meat starter culture (Lyocarni RBL-73, SACCO, Milano, Italy) consisting of Lactobacillus curvatus and Staphylococcus xylosus with $2.5 \times 10^{6} \log$ colony forming unit $(\mathrm{CFU}) / \mathrm{g}$ was added at a concentration of $6 \log \mathrm{CFU} / \mathrm{g}$. The starter culture and ingredients were added during mixing. The meat batter was then stuffed into $55 \mathrm{~mm}$ diameter fibrous casings (Seoul, Korea) using a stuffer (H20E, TALSA Co., Northampton, EU).

The salamis were then soaked for $2 \mathrm{~min}$ in Aspergillus spp. solution that was prepared using Aspergillus spp. obtained from the Korean Agricultural Culture Collection, National Academy of Agricultural Science, RDA. To prepare the solution, Aspergillus spp. were streaked onto Dichloran 18\% Glycerol Agar (DG18) (MBcell, Kisanbio, Seoul, Korea), then incubated at $25^{\circ} \mathrm{C}$ for 7 days. The fungal colonies were subsequently diluted with distilled water to produce the Aspergillus spp. solution, after which samples were dried and ripened in a laboratory dry-ripening room. The following conditions of relative humidity $(\mathrm{RH})$ and temperature were applied: day 0 until day $3,98 \% \mathrm{RH}$ and $20^{\circ} \mathrm{C} \pm 1^{\circ} \mathrm{C}$; day 4 until day $7,80 \%$ to $92 \% \mathrm{RH}$ and $18^{\circ} \mathrm{C} \pm 2^{\circ} \mathrm{C}$; day 7 until day 15 , $80 \%$ to $85 \% \mathrm{RH}$ and $18^{\circ} \mathrm{C} \pm 2^{\circ} \mathrm{C}$; after day $15,70 \%$ to $75 \% \mathrm{RH}$ and $16^{\circ} \mathrm{C}$.

All processes were done in three replication experimental design. Samples from each treatment were taken for proximate composition analyses from the raw mixture and after 20 and 40 days of ripening. Physicochemical and functional analyses were carried out on salami samples at the end of ripening. All results were expressed as the mean of triplicate trials on each sampling time.

\section{Proximate composition}

All determinations were conducted by analyzing a homogenized sample in triplicate. Moisture, fat, protein and ash were determined using methods of the AOAC with slight modifications [15].

\section{Nucleotide-related compounds}

The samples $(5 \mathrm{~g}$ ) were mixed with $25 \mathrm{~mL}$ of $0.7 \mathrm{M}$ perchloric acid, and centrifuged at $1,130 \mathrm{~g}$ for $1 \mathrm{~min}$ to extract the nucleic acids. The extracted nucleic acids were subsequently centrifuged at 2,090 $\mathrm{g}$ for $15 \mathrm{~min}$, after which they were filtered through a Whatman No. 4 filter paper (Whatman Inc., Pittsburgh, PA, USA). The supernatant was then adjusted to $\mathrm{pH} 7$ with $5 \mathrm{~N} \mathrm{KOH}$. Next, the $\mathrm{pH}$-adjusted supernatant was placed in a volumetric flask and diluted to a volume of $100 \mathrm{~mL}$ with $0.7 \mathrm{M}$ perchloric acid ( $\mathrm{pH}$ 7.0). After $30 \mathrm{~min}$ of cooling, the sample was centrifuged at $1,130 \mathrm{~g}\left(0^{\circ} \mathrm{C}\right)$, after which the supernatant was filtered through a $0.2 \mu \mathrm{m}$ polyvinylidene fluoride syringe filter (Whatman, Buckinghamshire, England). The filtrate $(5 \mathrm{~mL})$ was then analyzed using HPLC (ACME 9000, Younglin Instruments Inc, Anyang, Korea). With regard to the analytical conditions for high performance liquid chromatography (HPLC), a WatersAtlantis dC18 RP column $(4.6 \times 250 \mathrm{~mm}, 5 \mu \mathrm{m}$ particles, Waters Co., Milford, MA, USA) was utilized, with a mobile phase of $0.1 \mathrm{M}$ triethylamine in $0.15 \mathrm{M}$ acetonitrile ( $\mathrm{pH} 7.0$ ). The flow rate of the mobile phase was $1.0 \mathrm{~mL} / \mathrm{min}$ and the injection volume was $10 \mu \mathrm{L}$. The column temperature was maintained at $35^{\circ} \mathrm{C}$ and the detection was monitored at a wavelength of $260 \mathrm{~nm}$. The peaks of the individual nucleotides were identified using the retention times for standards: hypoxanthine, inosine, inosine- 5 '-phosphate (IMP), adenosine-5'-phosphate (AMP) (Sigma, St. Louis, MO, USA), and the concentration was calculated using the area for each peak.

\section{Fatty acid composition}

The total fat for fatty acid analysis was extracted as described by Nam et al [16]. After thawing the samples, the lipids in a $5 \mathrm{~g}$ sample were extracted in chloroform/methanol (2:1) using dibutyl hydroxy toluene as an antioxidant. The methyl esters from fatty acids were formed using a solution of $\mathrm{KOH}$ in methanol. The fatty acid methyl esters (FAME) were extracted with water and 
hexane, after which the top hexane layer containing FAME was dehydrated using anhydrous $\mathrm{Na}_{2} \mathrm{SO}_{4}$. The extracted and dehydrated hexane was then transferred to a vial for analysis. Separation and quantification of the fatty acid methyl esters was conducted using a gas chromatograph (Agilent 7890N, Agilent Technologies Seoul, Seoul, Korea) equipped with a flame ionization detector automatic sample injector HP 7693 using a DB-WAX fused silica capillary column $(30 \mathrm{~m}, 0.25 \mathrm{~mm}$ i.d., $0.2 \mathrm{~mm}$ film thickness, Agilent Technologies Seoul, Korea). Helium was applied as a carrier gas at a linear flow of $1 \mathrm{~mL} / \mathrm{min}$ and the injection volume was $1 \mu \mathrm{L}$. The oven temperature was initially held at $180^{\circ} \mathrm{C}$ for $1 \mathrm{~min}$, then increased at $2.5^{\circ} \mathrm{C} / \mathrm{min}$ to $230^{\circ} \mathrm{C}$, where it was held for $12 \mathrm{~min}$. The injector (split mode) and detector temperatures were maintained at $280^{\circ} \mathrm{C}$. Linoleic acid (C18:2) was used as an internal standard (catalogue number H3500, Sigma-Aldrich Inc., USA). FAMEs in total lipids were identified by comparison of the retention times with those of a standard FAME mixture (SuplecoTM 37 Component FAME Mix, Catalogue number 47885UP, Lot number, LB-85684. Sigma-Aldrich Inc., USA). Fatty acids were expressed as a percentage of total fatty acids identified and grouped as follows: saturated fatty acid (SFA), monounsaturated fatty acid (MUFA), and polyunsaturated fatty acid (PUFA). Finally, the PUFA/SFA and n-6/n-3 ratios were calculated.

\section{Free amino acids analysis}

The free amino acid composition was determined using a modification of the HPLC method described by Bidlingmeyer et al [17]. The meat was defatted by solvent extraction, then hydrolyzed with $6 \mathrm{~N} \mathrm{HCl}$ in a vacuum-sealed tube for $24 \mathrm{~h}$ at $110^{\circ} \mathrm{C}$, centrifuged and dried under vacuum for at least $1.5 \mathrm{~h}$. The $\mathrm{pH}$ was subsequently adjusted by adding $20 \mathrm{~mL}$ ethanol:water:triethylamine (2:2:1) and then dried as before. The samples were derivatized by adding $20 \mu \mathrm{L}$ ethanol:water:triethylamine:phen ylisothiocyanate $(7: 1: 1: 1)$ at room temperature $\left(26^{\circ} \mathrm{C}\right)$ for $10 \mathrm{~min}$, after which they were dried under vacuum for at least $3 \mathrm{~h}$. Next, the sample was re-suspended in $200 \mu \mathrm{L}$ Picotag (Waters, USA), of which $8 \mu \mathrm{L}$ were injected into an HPLC (Waters HPLC column,

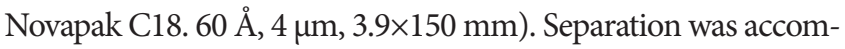
plished by using buffers: A (sodium acetate, $\mathrm{pH}$ 6.4, 5,000 ppm ethylenediaminetetraacetic acid (EDTA), triethylamine $(1: 2,000)$ and $6 \%, \mathrm{v} / \mathrm{v}$, acetonitrile) and $\mathrm{B}(60 \%, \mathrm{v} / \mathrm{v}$, acetonitrile and 5,000 ppm EDTA). A 1,525 HPLC with a binary gradient delivery, 717 autosampler and injector, 1,500 column heater and 2,487 dual wavelength UV detector were used in conjunction with the Breeze software Z (Waters, USA). The accuracy and repeatability of this analysis were ensured by the inclusion of a control sample of known amino acid composition with the samples prior to hydrolysis.

\section{Statistical analysis}

The experimental design consisted of curing salt $\times$ ripening time factorial analysis. Analysis of variance was performed on all variables using the general linear model procedure of the SAS statistical package (SAS Institute, Cary, NC, USA). Duncan's multiple range test $(\mathrm{p}<0.05)$ was used to identify differences among treatment means.

\section{RESULTS AND DISCUSSION}

\section{Proximate composition}

The effects of different curing agents on the proximate composition of salamis during the 20 days of ripening are shown in Table 1. The moisture content was highest in refined $\mathrm{NaCl}$ salt samples (T2) at day 0, whereas it was lowest in $\mathrm{KCl}$ samples (T3) at day 20 and $40(\mathrm{p}<0.05)$. These differences might have been due to the quicker penetration of the salt mixtures containing $\mathrm{KCl}$, which would hinder water retention from the inside of the meat [18]. These findings are in agreement with those reported by Lorenzo et al [13], who found significant differences in the moisture content of dry-cured ham prepared using different salting treatments. The fat content was highest in the $\mathrm{KCl}$ samples (T3) $(\mathrm{p}<0.05)$. Additionally the $\mathrm{MgCl}_{2}$ samples (T4) contained the highest protein contents, while sun-dried salt samples (T1) contained the lowest at day 20 and $40(\mathrm{p}<0.05)$. The ash content was

Table 1. Effects of different curing salts on the proximate composition of salamis during ripening

\begin{tabular}{|c|c|c|c|c|}
\hline \multirow{2}{*}{ Item } & \multicolumn{3}{|c|}{ Days of ripening } & \multirow{2}{*}{ SEM } \\
\hline & 0 & 20 & 40 & \\
\hline \multicolumn{5}{|c|}{ Moisture (\%) } \\
\hline$T 1^{1)}$ & $52.96^{\mathrm{Ba}}$ & $38.99^{\mathrm{Ab}}$ & $25.11^{\mathrm{Ac}}$ & 0.02 \\
\hline $\mathrm{T} 2$ & $53.55^{\mathrm{Aa}}$ & $24.27^{\mathrm{Bb}}$ & $20.79^{B C}$ & 0.02 \\
\hline $\mathrm{T} 3$ & $49.04^{\mathrm{Ca}}$ & $21.38^{\mathrm{Db}}$ & $16.74^{\mathrm{DC}}$ & 0.02 \\
\hline T4 & $48.27^{\text {Da }}$ & $23.36^{\mathrm{cb}}$ & $18.31^{\mathrm{Cc}}$ & 0.03 \\
\hline SEM & 0.04 & 0.03 & 0.03 & - \\
\hline \multicolumn{5}{|l|}{ Fat (\%) } \\
\hline T1 & $20.37^{c c}$ & $30.43^{\mathrm{Db}}$ & $40.01^{\mathrm{Ba}}$ & 0.09 \\
\hline $\mathrm{T} 2$ & $20.43^{c b}$ & $37.75^{\mathrm{Ca}}$ & $39.10^{\mathrm{Ca}}$ & 0.16 \\
\hline T3 & $22.13^{A b}$ & $44.97^{\mathrm{Aa}}$ & $43.79^{\mathrm{Aa}}$ & 0.08 \\
\hline T4 & $20.96^{B C}$ & $39.87^{\mathrm{Bb}}$ & $43.58^{\mathrm{Aa}}$ & 0.08 \\
\hline SEM & 0.02 & 0.02 & 0.06 & - \\
\hline \multicolumn{5}{|c|}{ Protein (\%) } \\
\hline $\mathrm{T} 1$ & $15.83^{c}$ & $20.82^{\mathrm{Cb}}$ & $27.30^{\mathrm{Da}}$ & 0.04 \\
\hline $\mathrm{T} 2$ & $15.98^{c}$ & $23.79^{B b}$ & $30.62^{\mathrm{Ca}}$ & 0.04 \\
\hline T3 & $15.88^{c}$ & $24.45^{\mathrm{Ab}}$ & $33.03^{\mathrm{Ba}}$ & 0.07 \\
\hline T4 & $16.18^{c}$ & $24.41^{\mathrm{Ab}}$ & $34.71^{\mathrm{Aa}}$ & 0.05 \\
\hline SEM & 0.03 & 0.05 & 0.07 & - \\
\hline \multicolumn{5}{|c|}{ Ash (\%) } \\
\hline T1 & $2.86^{\mathrm{AC}}$ & $3.75^{\mathrm{cb}}$ & $4.56^{\mathrm{Ba}}$ & 0.01 \\
\hline $\mathrm{T} 2$ & $2.55^{\mathrm{Cc}}$ & $4.03^{B b}$ & $4.61^{\mathrm{Ba}}$ & 0.01 \\
\hline T3 & $2.61^{\mathrm{BC}}$ & $4.12^{\mathrm{Ab}}$ & $4.96^{\mathrm{Aa}}$ & 0.01 \\
\hline T4 & $1.55^{D C}$ & $2.25^{\mathrm{Db}}$ & $2.64^{\mathrm{Ca}}$ & 0.01 \\
\hline SEM & 0.01 & 0.02 & 0.01 & - \\
\hline
\end{tabular}

SEM, Standard error of the means $(n=16)$.

1) $\mathrm{T} 1$, sun-dried salt $(\mathrm{NaCl}) ; \mathrm{T2}$, refined salt $(\mathrm{NaCl}) ; \mathrm{T3}, \mathrm{KCl} ; \mathrm{T} 4, \mathrm{MgCl}_{2}$.

${ }^{a-c}$ Figures with different letters within the same row differ significantly $(p<0.05)$.

${ }^{A-D}$ Figures with different letters within the same column differ significantly $(p<0.05)$. 
highest in sun-dried $\mathrm{NaCl}$ salt samples (T1) at day 0 , whereas it was lowest in $\mathrm{MgCl}_{2}$ samples (T4) at day 20 and 40 ( $\mathrm{p}<0.05$ ). The storage conditions had a significant effect on the proximate composition of the salamis $(\mathrm{p}<0.05)$. During ripening and drying, the moisture contents of salamis were significantly decreased at day 40 compared to day 0 , while the fat, protein, and ash contents increased $(\mathrm{p}<0.05)$. A similar trend was reported by Olivares et al [1], who found that the reduction in moisture of dry fermented sausages during ripening caused an increase in fat and protein contents. These results might be attributed to the exudation of water during ripening.

\section{Nucleotide-related compounds, fatty acids, and free} amino acids

Nucleotide-related compounds result from the decomposition of adenosine triphosphate (ATP) [19]. ATP is converted into adenosine diphosphate and adenosine monophosphate (AMP) by dephosphorylation, after which it becomes inosine monophosphate (IMP), which produces a nice flavor. However, IMP is degraded to inosine, and then to hypoxanthine, which has a bitter taste [20]. As shown in Table 2, T4 had higher AMP and hypoxanthine contents compared to the other samples $(p<0.05)$. T3 contained higher IMP, whereas T2 had more inosine $(\mathrm{p}<0.05)$. Although IMP has been shown to be linked to meat flavor, its disappearance does not mean a reduction in flavor intensity. This is because, in addition to the taste enhancing effect of salt, the mild ripening/drying conditions allow the generation of free amino acids and free fatty acids, which also contribute to taste [19].

The effects of different curing agents on the fatty acid composition of salamis are presented in Table 3. The major identified fatty acids were oleic (C18:1), palmitic (C16:0), linoleic (C18:2), stearic (C18:0), and palmitoleic (C16:1) acid in decreasing order. These findings agree with those of previous studies $[21,22]$. No significant differences were found in the fatty acid composition among treatments, with only slight differences in C12:0, C17:1, and C20:0 being observed. Additionally, T3 contained a higher percentage of C12:0, C17:1, and C20:0 when compared to the other treatments $(\mathrm{p}<0.05)$. Oleic acid $(\mathrm{C} 18: 1)$ made up the largest proportion of the MUFA, even though there was no significant difference between samples. Laranjo et al [22] have reported that

Table 2. Effects of different curing salts on nucleotide-related compounds (mg/100 g) of salamis after ripening

\begin{tabular}{lcccc}
\hline Item & AMP & IMP & Inosine & Hypoxanthine \\
\hline $\mathrm{T}^{1)}$ & $0.49^{\mathrm{c}}$ & $7.73^{\mathrm{b}}$ & $1.76^{\mathrm{b}}$ & $89.93^{\mathrm{c}}$ \\
$\mathrm{T} 2$ & $0.54^{\mathrm{bc}}$ & $7.79^{\mathrm{ab}}$ & $2.02^{\mathrm{a}}$ & $102.27^{\mathrm{b}}$ \\
$\mathrm{T} 3$ & $0.58^{\mathrm{b}}$ & $8.30^{\mathrm{a}}$ & $1.76^{\mathrm{b}}$ & $105.06^{\mathrm{b}}$ \\
$\mathrm{T} 4$ & $0.98^{\mathrm{a}}$ & $8.20^{\mathrm{ab}}$ & $1.56^{\mathrm{b}}$ & $111.54^{\mathrm{a}}$ \\
$\mathrm{SEM}$ & 0.018 & 0.160 & 0.070 & 1.593 \\
\hline
\end{tabular}

AMP, adenosine-5'-phosphate; IMP, inosine-5'-phosphate; SEM, standard error of the means $(n=16)$.

${ }^{1)} \mathrm{T} 1$, sun-dried salt $(\mathrm{NaCl}) ; \mathrm{T} 2$, refined salt $(\mathrm{NaCl}) ; \mathrm{T} 3, \mathrm{KCl} ; \mathrm{T} 4, \mathrm{MgCl}_{2}$.

${ }^{a-c}$ Figures with different letters within the same column differ significantly $(p<0.05)$.
Table 3. Effects of different curing salts on fatty acid composition of ripened salamis

\begin{tabular}{|c|c|c|c|c|c|}
\hline Item & $\mathrm{T} 1^{1)}$ & $\mathrm{T} 2$ & T3 & $\mathrm{T} 4$ & SEM \\
\hline C10:0 & 0.05 & 0.05 & 0.04 & 0.05 & 0.002 \\
\hline C12:0 & $0.08^{b}$ & $0.09^{b}$ & $0.12^{\mathrm{a}}$ & $0.08^{b}$ & 0.004 \\
\hline C14:0 & 1.46 & 1.38 & 1.45 & 1.35 & 0.06 \\
\hline C14:1 & 0.14 & 0.14 & 0.13 & 0.14 & 0.01 \\
\hline C15:0 & 0.09 & 0.09 & 0.09 & 0.08 & 0.01 \\
\hline C16:0 & 21.94 & 21.22 & 20.49 & 21.30 & 0.84 \\
\hline C16:1 & 2.24 & 2.26 & 2.23 & 2.09 & 0.09 \\
\hline C17:0 & 0.33 & 0.36 & 0.36 & 0.32 & 0.01 \\
\hline C17:1 & $0.31^{b}$ & $0.34^{b}$ & $0.40^{\mathrm{a}}$ & $0.31^{\mathrm{b}}$ & 0.02 \\
\hline C18:0 & 11.49 & 11.08 & 10.76 & 11.38 & 0.34 \\
\hline C18:1t & 0.15 & 0.17 & 0.18 & 0.16 & 0.03 \\
\hline C18:1 & 41.59 & 43.19 & 42.72 & 40.20 & 1.60 \\
\hline C18:2 & 11.77 & 12.28 & 12.15 & 10.84 & 0.48 \\
\hline$C 20: 0$ & $0.58^{c}$ & $0.70^{b}$ & $0.83^{\mathrm{a}}$ & $0.63^{c}$ & 0.02 \\
\hline C18:3 & 0.41 & 0.22 & 0.24 & 0.25 & 0.10 \\
\hline$C 20: 2$ & 0.51 & 0.56 & 0.40 & 0.35 & 0.09 \\
\hline$C 20: 3$ & 0.13 & 0.16 & 0.20 & 0.20 & 0.03 \\
\hline C2O:4 & 0.46 & 0.54 & 0.55 & 0.53 & 0.03 \\
\hline C24:1 & 0.27 & 0.14 & 0.16 & 0.16 & 0.06 \\
\hline SFA & 36.01 & 34.96 & 34.14 & 35.16 & 1.25 \\
\hline UFA & 59.29 & 59.92 & 59.29 & 55.12 & 2.13 \\
\hline MUFA & 44.59 & 46.17 & 45.76 & 42.97 & 1.70 \\
\hline PUFA & 13.28 & 13.75 & 13.54 & 12.15 & 0.44 \\
\hline UFA/SFA & $1.61^{b}$ & $1.71^{\mathrm{a}}$ & $1.74^{\mathrm{a}}$ & $1.57^{c}$ & 0.01 \\
\hline
\end{tabular}

SEM, standard error of the means $(n=16)$; SFA, saturated fatty acid; UFA, unsaturated fatty acid; MUFA, monounsaturated fatty acid; PUFA, polyunsaturated fatty acid.

1) $\mathrm{T} 1$, sun-dried salt $(\mathrm{NaCl}) ; \mathrm{T2}$, refined salt $(\mathrm{NaCl}) ; \mathrm{T}, \mathrm{KCl} ; \mathrm{T} 4, \mathrm{MgCl}_{2}$.

${ }^{a-c}$ Figures with different letters within the same row differ significantly $(p<0.05)$.

oleic acid was not changed by salt types.

The free amino acid contents of ripened samples with different curing salts are shown in Table 4. Tseng et al [23] classified free amino acids in food as being related to umami (aspartic acid, glutamic acid), sweet (serine, glycine, threonine, alanine), bitter (valine, methionine, isoleucine, leucine, phenylalanine, histidine, arginine), and other tastes (glutamine, tyrosine, lysine, and proline). The free amino acids of salami (T3) salted with $\mathrm{KCl}$ was rated equally to those with $\mathrm{NaCl}$. T4 samples showed the highest content of total free amino acids than the other samples $(\mathrm{p}<0.05)$. As free amino acid content was used as a measure of proteolytic activity [24,25], the substitution of $\mathrm{NaCl}$ by $\mathrm{MgCl}_{2}$ seemed to increase proteolysis.

According to Toldra [26], aminopeptidases could be activated in the presence of salt, and may contribute to the generation of free amino acids. Of the free amino acids, a higher arginine concentration was observed in T4 samples $(\mathrm{p}<0.05)$. Fujimura et al [27] reported that the interaction between glutamic acid and inosine acid (IMP) enhanced the taste of meat products. T4 contained higher aspartic acid (Asp), threonine (Thr), alanine (Ala), leucine (Leu), isoleucine (Ile), and phenylalanine (Phe) concentrations than the other samples $(\mathrm{p}<0.05)$, which can have a negative impact on the sensory quality, as high concentrations of Met, Leu, and Ile may increase the bitter taste of dry fermented sausages 
Table 4. Effects of different curing salts on free amino acids (mg/100 g) of ripened salamis

\begin{tabular}{|c|c|c|c|c|c|}
\hline Item & $\mathrm{T} 1^{1)}$ & $\mathrm{T} 2$ & T3 & T4 & SEM \\
\hline Taurine & $27.39^{b}$ & $34.01^{\mathrm{a}}$ & $35.32^{\mathrm{a}}$ & $33.28^{\mathrm{a}}$ & 1.13 \\
\hline Aspartic acid & $21.26^{b}$ & $27.31^{b}$ & $29.30^{b}$ & $48.28^{a}$ & 1.10 \\
\hline Threonine & $34.43^{c}$ & $39.19^{b}$ & $37.55^{b c}$ & $54.40^{\mathrm{a}}$ & 0.98 \\
\hline Serine & $32.64^{c}$ & $48.71^{b}$ & $45.39^{b}$ & $72.91^{\mathrm{a}}$ & 1.45 \\
\hline Asparagine & $109.94^{b}$ & $116.78^{b}$ & $105.08^{b}$ & $160.49^{\mathrm{a}}$ & 3.24 \\
\hline Glutamic acid & 14.04 & 16.66 & 12.00 & 17.98 & 1.34 \\
\hline Proline & 3.44 & 3.20 & 4.70 & 2.75 & 0.45 \\
\hline Glycine & $66.35^{b}$ & $63.85^{b}$ & $57.34^{c}$ & $98.48^{\mathrm{a}}$ & 1.97 \\
\hline Alanine & $102.58^{c}$ & $135.52^{b}$ & $130.53^{b}$ & $159.20^{\mathrm{a}}$ & 3.14 \\
\hline Valine & $45.10^{b}$ & $48.74^{\mathrm{ab}}$ & $48.71^{\mathrm{ab}}$ & $53.14^{a}$ & 1.26 \\
\hline Cystine & $25.98^{b}$ & $28.99^{b}$ & $25.98^{b}$ & $43.07^{\mathrm{a}}$ & 0.84 \\
\hline Methionine & $1.31^{\mathrm{a}}$ & $1.07^{b}$ & $1.03^{b}$ & $0.48^{c}$ & 0.05 \\
\hline Isoleucine & $25.53^{c}$ & $29.25^{b}$ & $27.25^{b c}$ & $35.33^{\mathrm{a}}$ & 0.71 \\
\hline Leucine & $75.13^{c}$ & $92.19^{b}$ & $87.05^{b}$ & $129.88^{\mathrm{a}}$ & 2.00 \\
\hline Tyrosine & $1.60^{b}$ & $1.87^{b}$ & - & $7.18^{\mathrm{a}}$ & 0.14 \\
\hline Phenylalanine & $28.24^{d}$ & $31.81^{b}$ & $27.38^{c}$ & $55.37^{\mathrm{a}}$ & 1.07 \\
\hline Histidine & $23.82^{\mathrm{ab}}$ & $21.94^{b}$ & $23.72^{\mathrm{ab}}$ & $27.14^{\mathrm{a}}$ & 0.98 \\
\hline Tryptophan & 11.69 & 12.91 & 13.78 & 13.59 & 0.55 \\
\hline Carnosine & $25.21^{c}$ & $32.27^{b}$ & $21.83^{b}$ & $42.53^{\mathrm{a}}$ & 0.74 \\
\hline Lysine & $59.11^{b}$ & $57.34^{b}$ & $56.33^{b}$ & $72.07^{\mathrm{a}}$ & 1.13 \\
\hline Ammonia & $75.11^{c}$ & $91.86^{b}$ & $82.99^{c}$ & $105.72^{\mathrm{a}}$ & 2.53 \\
\hline Arginine & $8.90^{\mathrm{ab}}$ & $6.11^{\mathrm{ab}}$ & $4.40 \mathrm{~b}$ & $10.47^{\mathrm{a}}$ & 1.27 \\
\hline Tasty $\mathrm{AA}^{2)}$ & $421.05^{c}$ & $472.87^{b}$ & $441.99^{b c}$ & $614.41^{\mathrm{a}}$ & 10.89 \\
\hline Bitter $A A^{3)}$ & $126.59^{b}$ & $137.85^{b}$ & $131.46^{b}$ & $181.44^{\mathrm{a}}$ & 3.42 \\
\hline Tasty/bitter AA & $3.26^{b}$ & $3.43^{\mathrm{a}}$ & $3.36^{\mathrm{ab}}$ & $3.39^{\mathrm{ab}}$ & 0.04 \\
\hline Total amino acids & $823.80^{c}$ & $940.88^{b}$ & $887.66^{b c}$ & $1,243.7^{\mathrm{a}}$ & 20.60 \\
\hline
\end{tabular}

SEM, standard error of the means $(n=16) ; A A$, amino acid.

1) $\mathrm{T} 1$, sun-dried salt $(\mathrm{NaCl}) ; \mathrm{T} 2$, refined salt $(\mathrm{NaCl}) ; \mathrm{T3}, \mathrm{KCl} ; \mathrm{T} 4, \mathrm{MgCl}_{2}$.

${ }^{2)}$ Serine+asparagine+glutamate+glycine+alanine.

${ }^{3)}$ Valine+isoleucine+phenylalanine+histidine+arginine.

${ }^{a-d}$ Figures with different letters within the same row differ significantly $(p<0.05)$.

[19]. This free amino acid is responsible for the flavor development that is characteristic of dry-cured meat products [28]. Similarly, no difference was observed in the total free amino acids in cured loins prepared with a partial replacement of $\mathrm{NaCl}$ by $\mathrm{KCl}$ [25]. In terms of the ratio of tasty and bitter amino acids, T2 had greater value than T1. The lowest ratio value of T1 can be attributed to the relatively higher content of impurities. Consequently, there were very few differences in amino acid composition between $\mathrm{NaCl}$ and $\mathrm{KCl}$ samples, while $\mathrm{MgCl}_{2}$ showed the highest total free amino acids contents than the others $(\mathrm{p}<0.05)$. This result can be attributed to the difference of ionic valence of added curing salts.

\section{CONCLUSION}

The use of NaCl-alternative salts showed beneficial impacts on the proximate composition of salamis with reduction of sodium and increase of protein content. Salamis with $\mathrm{KCl}$ addition showed higher contents of flavor compounds derived from nucleic acids and fatty acids. On the other hand, $\mathrm{MgCl}_{2}$ increased production of free amino acids induced by accelerated protein degradation. The different proteolytic patterns by alternative curing salts can be attributed to the different atomic valences $(-1$ or -2$)$ of the added salts. These results suggest that substitution with $\mathrm{KCl}$ can be employed as a means of sodium reduction in salamis. Therefore, this could be utilized to lower the sodium content in salami without having an adverse effect on physicochemical traits, demonstrating a potential application of the salami formulation with $\mathrm{KCl}$ in the market. However, further studies should investigate the effects of salt reduction and/or salt substitution on the microbial and sensory tests for consumer acceptance.

\section{CONFLICT OF INTEREST}

We certify that there is no conflict of interest with any financial organization regarding the material discussed in the manuscript.

\section{ACKNOWLEDGMENTS}

This study was supported by the research fund of Economy Cooperation Supporting Business (R005730-1), Ministry of Trade, Industry and Energy.

\section{REFERENCES}

1. Olivares A, Navarro JL, Salvador A, Flores M. Distribution of volatile compounds in lean and subcutaneous fat tissues during processing of dry fermented sausages. Food Res Int 2009;42:1303-8.

2. Comi G, Orlic S, Redzepovic S, Urso R, Iacumin L. Moulds isolated from Istrian dried ham at the pre-ripening and ripening. Int J Food Microbiol 2004;96:29-34.

3. Nunez F, Rodriguez MM, Bermudez ME, Cordoba JJ, Asensio MA. Composition and toxigenic potential of the mould population on dry-cured Iberian ham. Int J Food Microbiol 1996;32:185-97.

4. Martin M. Meat curing technology. In: Hui YH, Nip WK, Rogers RW, Young AO, editors. Meat science and applications. New York, USA: Marcel Dekker; 2001. pp. 491-508.

5. WHO. Strategies to monitor and evaluate population sodium consumption and sources of sodium in the diet. [Internet]. World Health Organization; 2011 [cited 2017 Apr 20]. Available from: http://apps. who.int/iris/handle/10665/44614

6. Ruusunen M, Puolanne E. Reducing sodium intake from meat products. Meat Sci 2005;70:531-41.

7. Sebranek JG, Bacus JN. Cured meat products without direct addition of nitrate or nitrite: what are the issues? Meat Sci 2007;77:136-47.

8. Olesen PT, Meyer AS, Stahnke LH. Generation of flavor compounds in fermented sausages-the influence of curing ingredients, Staphylococcus starter culture and ripening time. Meat Sci 2004;66:675-87.

9. Choi YS, Jeong TJ, Hwang KE, et al. Effects of various salts on physicochemical properties and sensory characteristics of cured meat. Korean J Food Sci An 2016;26:229-35.

10. Ha JO, Park KY. Comparison of mineral contents and external struc- 
ture of various salts. J Korean Soc Food Sci Nutr 1998;27:413-8.

11. US FDA. Code of federal regulations. [Internet]. Food and Drug Administration; 2010 [cited 2017 Apr 20]. Available from: https:// www.accessdata.fda.gov/scripts/cdrh/cfdocs/cfcfr/CFRSearch.cf $\mathrm{m} ? \mathrm{fr}=184.1622 \&$ SearchTerm $=$ potassium $\% 20$ chloride

12. Aburto NJ, Hanson S, Gutierrez H, et al. Effect of increased potassium intake on cardiovascular risk factors and disease: systematic review and meta-analyses. BMJ 2013;346:f1378.

13. Lorenzo JM, Bermudez R, Dominguez R, et al. Physicochemical and microbial changes during the manufacturing process of dry-cured lacon salted with potassium, calcium and magnesium chloride as a partial replacement for sodium chloride. Food Control 2015;50:763-9.

14. Guardia MD, Guerrero L, Gelabert J, Gou P, Arnau J. Sensory characterization and consumer acceptability of small calibre fermented sausages with $50 \%$ substitution of $\mathrm{NaCl}$ by mixtures of $\mathrm{KCl}$ and potassium lactate. Meat Sci 2008;80:1225-30.

15. AOAC. Official methods of analysis. 17th ed. Gaithersburg, MD: Association of Official Analytical Chemists; 2000.

16. Nam KC, Kim HC, Cha J, Yim DG. The quality characteristics and antioxidant properties of sun-dried venison jerky with green tea powder during storage. Korean J Food Sci An 2016;36:626-34.

17. Bidlingmeyer B, Cohen SA, Tarvin TL. Rapid analysis of amino acids using pre-column derivatisation. J Chromatogr 1984;336:93-104.

18. Alino M, Grau R, Toldra F, et al. Influence of sodium replacement on physicochemical properties of dry-cured loin. Meat Sci 2009;83: 423-30.

19. Flores M, Armero E, Aristoy MC, Toldra F. Sensory characteristics of cooked pork loin as affected by nucleotide content post-mortem meat quality. Meat Sci 1999;51:53-9.

20. Tikk M, Tikk K, Torgen MA, et al. Development of inosine monophosphate and its degradation products during aging of pork of different qualities in relation to basic taste and retronasal flavor perception of the meat. J Agric Food Chem 2006;54:7769-77.

21. Elias M, Carrascosa AV. Characterization of the Paio do Alentejo, a traditional Portuguese Iberian sausage, in respect to its safety. Food Control 2010;21:97-102.

22. Laranjo M, Agulheiro-Santos AP, Potes ME, et al. Effects of genotype, salt content and caliber on quality of traditional dry-fermented sausages. Food Control 2015;56:119-27.

23. Tseng YH, Lee RC, Li JL, Mau JL. Nonvolatile flavour components of Ganoderma tsugae. Food Chem 2005;90:409-15.

24. Armenteros M, Arostoy M, Barat JM, Toldra F. Biochemical and sensory changes in dry-cured ham salted with partial replacements of $\mathrm{NaCl}$ by other chloride salts. Meat Sci 2012;90:361-7.

25. Toldrá $\mathrm{F}$. The role of muscle enzymes in dry-cured meat products with different drying conditions. Trends Food Sci Technol 2006;17: 164-8.

26. Toldra F. Manufacturing of dry-cured ham. In: Toldra F, Editor. Drycured meat products. Trumbull; 2002. pp. 27-62.

27. Fujimura S, Koga H, Takeda H, et al. Role of taste active components, glutamic acid, 5- inosinic acid and potassium ion in taste of chicken meat extract. Anim Sci Technol 1996;67:423-9.

28. Dos Santos BA, Campagnol PCB, Cavalcanti RN, et al. Impact of sodium chloride replacement by salt substitutes on the proteolysis and rheological properties of dry fermented sausages. Food Eng 2015; 151:16-24. 